\title{
Clinical Pharmacology of Corticosteroids
}

\section{Dennis M Williams PharmD BCPS AE-C}

\author{
Introduction \\ Hypothalamic-Pituitary-Adrenal Axis Physiology \\ Glucocorticoids \\ Effects \\ Mechanism of Action (Anti-Inflammatory and Immunosuppressive Effects) \\ Structure \\ Agents for Systemic Therapy \\ Available Agents \\ Pharmacodynamics and Pharmacokinetics \\ Uses \\ Adverse Drug Reactions and Side Effects \\ Minimizing Hypothalamic-Pituitary-Adrenal Axis Suppression \\ Tapering of Corticosteroid Therapy \\ Drug Interactions \\ Inhaled Corticosteroids \\ Pharmacodynamics and Pharmacokinetics \\ Receptor Affinity, Lipophilicity, and Bioavailability \\ Potency \\ Dose-Response \\ Therapeutic Index \\ Disposition \\ Adverse Drug Reactions and Side Effects \\ Drug Interactions \\ Clinical Applications in Lung Disease \\ Asthma \\ COPD \\ Summary
}

Corticosteroids have numerous applications in treating inflammation and diseases of immune function based on their significant anti-inflammatory and immunosuppressive effects. Corticosteroids modulate immune function through various effects in the nucleus of numerous cells. When used in pharmacologic doses to suppress allergic responses or inflammation, these agents can cause numerous adverse effects associated with an excess of glucocorticoid activity. Prolonged use ( $>2 \mathrm{wk}$ ) results in suppression of the hypothalamic-pituitary-adrenal axis, which requires tapering of doses. Dosing strategies for systemic corticosteroids are designed to minimize the risk for hypothalamicpituitary-adrenal axis suppression. Topical administration of corticosteroids, including oral inhalation, is often used to avoid the significant adverse effects associated with chronic use. Inhaled corticosteroids are potent synthetic agents that exert their actions locally in the airways but can cause systemic effects based on several factors that influence systemic bioavailability. Inhaled corticosteroids are the cornerstone of asthma therapy and important options for COPD in patients who experience frequent exacerbations. By the nasal route, they are the most effective therapy for treating moderate-to-severe allergic rhinitis. Key words: COPD; asthma corticosteroids; lung disease. [Respir Care 2018;63(6):655-670. (C) 2018 Daedalus Enterprises] 


\section{Introduction}

Corticosteroids are important therapeutic agents used to treat allergic and inflammatory disorders or to suppress undesirable or inappropriate immune system actions. The term corticosteroid is used clinically to describe agents with glucocorticoid activity. Cortisol is the endogenous glucocorticoid, named for its effects on glucose metabolism but which also exerts the other immunological actions of corticosteroids. Cortisol is produced in the adrenal gland through cholesterol metabolism. A variety of other hormones, including mineralocorticoid, aldosterone, and male and female sex hormones, are produced through the common pathway of cholesterol metabolism. This common pathway and structural similarities among the hormones help to explain some of the side effects and adverse reactions associated with pharmacologic doses of cortisol and its synthetic analogues.

\section{Hypothalamic-Pituitary-Adrenal Axis Physiology}

Endogenous cortisol production by the adrenal gland is controlled by the hypothalamic-pituitary-adrenal axis and occurs in a diurnal and circadian pattern every $24 \mathrm{~h}$. Corticotrophin-releasing hormone is released from the hypothalamus and acts on the anterior pituitary to release adrenocorticotrophic hormone, which stimulates cortisol production and release from the adrenal gland. ${ }^{1}$ Exogenously administered adrenocorticotrophic hormone results in an increase in serum cortisol and is an older therapy that has limited clinical utility today. Plasma cortisol concentrations are typically highest in the morning (eg, 10-15 $\mu \mathrm{g} / \mathrm{mL}$ at $6: 00-8: 00 \mathrm{AM}$ ), and lowest during the night while sleeping. Circulating cortisol exerts negative feedback on adrenocorticotrophic hormone and corticotrophinreleasing hormone production. ${ }^{2,3}$ Normal hypothalamicpituitary-adrenal axis function is important for general health and well-being. Under non-stressed conditions, cortisol production is approximately $20 \mathrm{mg}$ daily in adults.

Dr Williams is affiliated with Division of Pharmacotherapy and Experimental Therapeutic, Eshelman School of Pharmacy, University of North Carolina, Chapel Hill, North Carolina.

Dr Williams has no conflicts to disclose.

Dr Williams presented a version of this paper at the 56th RESPIRATORY CARE Journal Conference, Respiratory Medications for COPD and Adult Asthma: Pharmacologic Actions to Clinical Applications, held June 2223, 2017 in St Petersburg, Florida.

Correspondence: Dennis M Williams PharmD BCPS AE-C, Eshelman School of Pharmacy, Kerr Hall, CB 7569, University of North Carolina, Chapel Hill, North Carolina 27599. E-mail: dwilliams@ unc.edu.

DOI: $10.4187 /$ respcare. 06314
In addition to the normal production and control of cortisol secretion, physical or psychological stress also is associated with increased levels of cortisol. Examples of stress include infection, major trauma, and diseases. There is clinical evidence that the daily production can increase to $150-200 \mathrm{mg}$ during physical or mental stress. ${ }^{1}$ In serious chronic disease associated with inflammation, including sepsis, the adrenal gland's ability to produce cortisol at maximal levels is impaired. This situation is described as relative adrenal insufficiency, and supplementation with hydrocortisone may be warranted. ${ }^{4}$

The adrenal gland consists of 3 functional zones. Cortisol is the product of cholesterol metabolism in the zona fasciculate. ${ }^{1}$ The primary mineralocorticoid, aldosterone, is produced in the zona glomerulosa, whereas androgens and sex hormones, including progesterone, estrogens, and testosterone, are produced in the zona fasciculate and zona reticularis. A functioning and intact hypothalamic-pituitary-adrenal axis is important for maintaining health and metabolic functions. Mineralocorticoid activity through aldosterone is primarily controlled by the renin-angiotensinaldosterone system as well as by serum potassium concentrations. Although cortisol and aldosterone control specific functions, both agents possess qualities affecting the other system due to their structural similarities and because they are derivatives of cholesterol.

\section{Glucocorticoids}

\section{Effects}

As the primary endogenous glucocorticoid, cortisol has a variety of physiologic effects in humans. These effects are pleiotropic and pedestrian, and affect nearly every organ and metabolic process in the body. Pharmacologic use of corticosteroids is commonly to suppress or prevent signs and symptoms of allergic responses or inflammation, or to suppress an inappropriate or unwanted immune response. Less commonly, hydrocortisone is used for physiologic replacement of cortisol when the hypothalamic-pituitaryadrenal axis is present or circulating cortisol is deficient due to a primary adrenal condition or due to a secondary failure of the pituitary or hypothalamus, which results in deficits of adrenocorticotrophic hormone or corticotrophinreleasing hormone.

Corticosteroid effects on inflammation and immune function are described below. In addition, these agents affect carbohydrate, protein, and lipid metabolism, which results in gluconeogenesis, protein catabolism, and fatty acid mobilization, along with multiple other effects. Corticosteroids also affect bone and calcium metabolism, cardiovascular homeostasis, central nervous system function, and a variety of endocrine effects. ${ }^{2}$ There also are effects on cardiovascular function and fluid and electrolyte bal- 


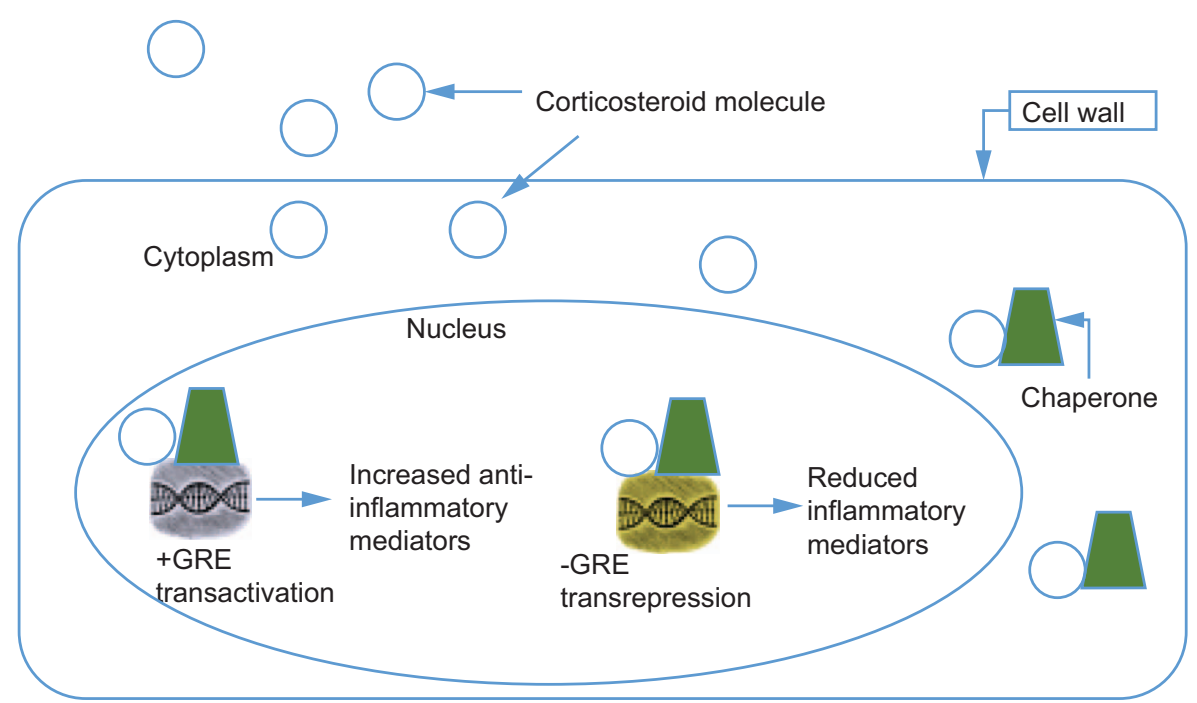

Fig. 1. Corticosteroid mechanism of action. GRE = glucoid response elements.

ance that are attributed both to glucocorticoid and mineralocorticoid activity. With pharmacologic dosing of corticosteroids, these effects are significant and often undesirable, which results in physiologic consequences that are described in the adverse drug reactions and side effects section.

Although corticosteroids are used primarily for their anti-inflammatory effects, they also are associated with beneficial effects on the $\beta_{2}$-adrenergic receptor. ${ }^{5}$ Corticosteroids are associated with upregulation of $\beta_{2}$-adrenergic receptor function as well as acting to reverse downregulation of these receptors associated with chronic $\beta_{2}$-adrenergic therapies. Plausible mechanisms for this effect at the $\beta_{2}$-adrenergic receptor are to increase coupling of $\beta$ receptors to $\mathrm{G}$ proteins, which increases adenyl cyclase, and to also increase the synthesis of new receptors. ${ }^{5}$

\section{Mechanism of Action (Anti-Inflammatory and Immunosuppressive Effects)}

Corticosteroids represent important and life-saving therapy when anti-inflammatory or immunosuppressive effects are needed. Corticosteroids affect numerous steps in the inflammatory pathway, which enhance their utility. To exert an effect, the steroid molecule diffuses across cell membranes and binds to glucocorticoid receptors, which causes a conformational change in the receptor. ${ }^{6}$ The receptorglucocorticoid complex is able to move into the cell nucleus, where it dimerizes and binds to glucocorticoid response elements (Fig. 1). Glucocorticoid response elements are associated with genes that either suppress or stimulate transcription, which results in ribonucleic acid and protein synthesis; these effects are called transrepression or transactivation, respectively. ${ }^{7}$ Ultimately, these agents inhibit transcription factors that control synthesis of pro-inflammatory mediators, including macrophages, eosinophils, lymphocytes, mast cells, and dendritic cells. 6,8,9 Another important effect is inhibition of phospholipase A2, which is responsible for production of numerous inflammatory mediators. ${ }^{10}$

Corticosteroids inhibit genes responsible for expression of cyclooxygenase-2, inducible nitric oxide synthase, and pro-inflammatory cytokines, including tumor necrosis factor alpha and various interleukins. In contrast, corticosteroids initiate upregulation of lipocortin and of annexin A1, a protein that reduces prostaglandin and leukotriene synthesis and that also inhibits cyclooxygenase- 2 activity and reduces neutrophil migration to inflammatory sites. Because corticosteroid action occurs intracellularly, the effects persist, even when detection in the plasma is absent.

\section{Structure}

All steroid hormones are derived from cholesterol metabolism. The shared chemical feature of cortisol and synthetic analogues, including systemic and topical therapies, is a 17-carbon androstane structure that originates from cholesterol metabolism. There are three 6-carbon hexane rings and one 5-carbon pentane ring (Fig. 2). ${ }^{11}$ The key characteristic of steroid molecules responsible for glucocorticoid activity is the presence of a hydroxyl group at carbon 11. Agents that have 2 carbons at position 17 on the pentane ring and methyl groups at the carbon 18 and 19 position are referred to as glucocorticoids because of their activity with glucose metabolism. Other modifications to the structure can increase potency or reduce mineralocorticoid activity. 


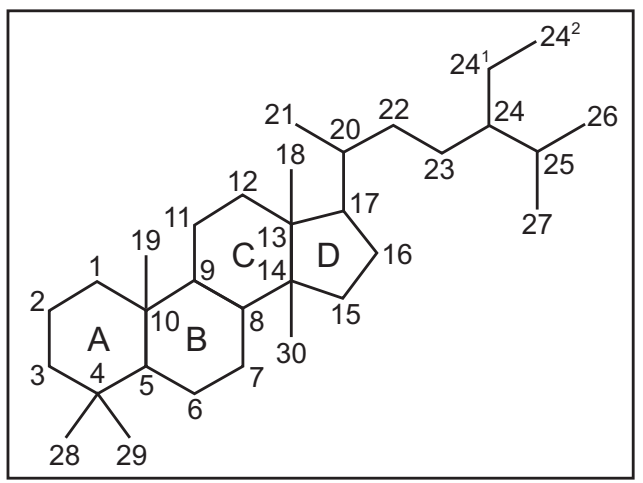

Fig. 2. Corticosteroid molecule.

Two clinically used corticosteroid agents, cortisone and prednisone, have a ketone group at carbon 11 and require hepatic activation to active the hydroxyl compounds hydrocortisone and prednisolone, respectively. ${ }^{1}$ Hydrocortisone is the clinical name for cortisol. There are numerous corticosteroid agents that have been developed for topical use (eg, creams, ointments, enemas, ophthalmics, nasal and oral inhalation, intra-articular injections) and are biologically active with the carbon-11 hydroxyl group.

The addition of esters at carbons 16 and 17 and of hydrophobic groups at carbons 20 and 21 improve affinity for the glucocorticoid receptor. For synthetic agents, the addition of a halogen and a 1,2 double bond on carbons 6 and 9 results in improved potency and stability against metabolism. In general, the structural modifications result in improved specificity for the glucocorticoid receptor, a longer duration of receptor occupancy, increased lipophilicity, and reduced aqueous solubility. ${ }^{12}$ These features are desirable pharmacologic properties to enhance efficacy and safety.

\section{Agents for Systemic Therapy}

Systemic therapy with corticosteroids is typically administered orally, intravenously, or intramuscularly. Shortterm use can be life-saving. Chronic use, even at low doses, is associated with significant adverse consequences, so that systemic corticosteroids are rarely, if ever, the preferred treatment for chronic conditions. However, their use is sometimes unavoidable in immunologic diseases, which are inadequately controlled with alternate therapies.

\section{Available Agents}

Clinically relevant systemic glucocorticoids are listed in Table 1. Of note, prednisone undergoes hepatic conversion to prednisolone for activation. The hepatic conversion is nearly $100 \%$, even in the presence of significant hepatic dysfunction, so the effects of these 2 agents are virtually identical. Cortisone also undergoes hepatic conversion to hydrocortisone, and this activation is impaired in patients with significant hepatic dysfunction, which limits the use of this therapy. Corticosteroid products can be classified according to characteristics that include the duration of suppression of the hypothalamic-pituitary-adrenal axis. ${ }^{13}$

\section{Pharmacodynamics and Pharmacokinetics}

Corticosteroids systemically used are classified according to potency, mineralocorticoid effects, and duration of hypothalamic-pituitary-adrenal axis suppression. Potency is expressed relative to hydrocortisone and is useful in determining comparable doses. Mineralocorticoid activity is also described relative to hydrocortisone, and structural modifications to the steroid molecule are designed to increase potency as well as to minimize mineralocorticoid effects when these agents are used in pharmacologic doses to prevent or treat allergic, inflammatory, or immune responses. Although more-potent agents exhibit fewer mineralocorticoid effects, in the doses normally used, side effects are common with all available agents. Finally, these agents are classified as short, medium, or long acting based on the duration of hypothalamic-pituitary-adrenal axis suppression. The duration of action is not well correlated with the duration of effect, possibly due to the intracellular mechanism. Because the mechanism of corticosteroids is intracellular, the effects persist even after corticosteroids have disappeared from the circulation. Therefore, the duration of action for specific corticosteroids is often based on how long effects on the hypothalamic-pituitary-adrenal axis persist, whereas the actual therapeutic action is longer. The onset of effect of systemic corticosteroids is often delayed for 3-8 h, regardless of the route of administration. This may be related to the intracellular and nuclear effect of these therapies. When the anti-inflammatory effect is seen, it is often dramatic. For life-threatening conditions, the acute use of systemic corticosteroids should not be delayed.

\section{Uses}

Systemic corticosteroids are used for physiologic replacement of glucocorticoids and for pharmacologic purposes to suppress inflammation and immune system reactions that are either undesirable or inappropriate. Pharmacologic doses of corticosteroids exceed the normal physiologic doses. Pharmacologic doses of systemic corticosteroid therapy may be indicated for short-term use when an inflammatory or immune response presents serious and life-threatening risks to the patient, including for exacerbations of asthma or COPD. When warranted, systemic doses should be administered early in 
Table 1. Systemic Corticosteroid Properties

\begin{tabular}{|c|c|c|c|c|}
\hline Medication & $\begin{array}{l}\text { Anti-Inflammatory } \\
\text { Potency (relative) }\end{array}$ & $\begin{array}{c}\text { Equivalent } \\
\text { Potency (mg) }\end{array}$ & $\begin{array}{c}\text { Duration of Effect } \\
\text { (hypothalamic-pituitary-adrenal } \\
\text { axis) (h) }\end{array}$ & $\begin{array}{l}\text { Mineralocorticoid } \\
\text { Potency (relative) }\end{array}$ \\
\hline \multicolumn{5}{|l|}{ Short acting } \\
\hline Hydrocortisone & 1 & 20 & $8-12$ & 1 \\
\hline \multicolumn{5}{|l|}{ Intermediate acting } \\
\hline Prednisone & 4 & 5 & $18-36$ & 0.8 \\
\hline Prednisolone & 4 & 5 & $18-36$ & 0.8 \\
\hline Methylprednisolone & 5 & 4 & $18-36$ & 0.5 \\
\hline \multicolumn{5}{|l|}{ Long acting } \\
\hline Dexamethasone & 25 & 0.75 & $>36$ & 0 \\
\hline
\end{tabular}

treatment based on the delayed onset ( $3-8 \mathrm{~h}$ ) for many conditions.

Although systemic corticosteroids are often warranted for acute flares or exacerbations of serious conditions, they are not considered first-line therapy for chronic management because of the common and significant adverse consequences. Chronic systemic corticosteroid therapy may be required in diseases that are unresponsive to first-line and preferred therapies but require close monitoring for the numerous adverse effects associated with chronic use. When pharmacologic therapy, which is the most common use of systemic steroids, is used, synthetic products with increased potency and minimal mineralocorticoid activity are preferred.

Physiologic replacement of cortisol may be required in cases of hypothalamic-pituitary-adrenal axis suppression or failure. The goal of replacement therapy is to mimic levels of cortisol in the blood present during normal, unstressed situations as well as during physiologic or mental stress to prevent signs and symptoms of adrenal insufficiency. When hypothalamic-pituitary-adrenal axis suppression is present as a result of prolonged corticosteroid use, the return to normal hypothalamic-pituitary-adrenal axis function and response may require 12 months after discontinuation of the corticosteroid.

Hydrocortisone is the agent of choice for physiologic replacement. Usual dosing strategies to mimic normal cortisol production is $20 \mathrm{mg}$ each morning and $10 \mathrm{mg}$ at $4: 00$ PM. During periods of stress, doses of up to $300 \mathrm{mg}$ daily may be required to prevent signs and symptoms of adrenal insufficiency, including hypoglycemia, hypotension, and cardiovascular collapse. Dosage titration and optimization of chronic therapy may be required to prevent symptoms. Fludrocortisone is a synthetic form of aldosterone that can be added to improve overall control of adrenal insufficiency and is generally dosed at $0.1 \mathrm{mg}$ daily.

\section{Adverse Drug Reactions and Side Effects}

Chronic treatment with systemic corticosteroids is associated with numerous and significant risks for adverse reactions and toxicities. These agents affect every organ system and metabolic process in humans. The risk for adverse effects from corticosteroid therapy is related to the dose and the duration of therapy as well as the specific agent used. ${ }^{14}$ Historically, short courses of systemic corticosteroids were not thought to cause significant longlasting toxicities, although a recent report refutes this safety claim..$^{15}$ It is well established that chronic administration of corticosteroids, even at physiologic doses, can cause undesirable effects and toxicities. The most significant adverse effect, and one that is associated with other toxicities, is hypothalamic-pituitary-adrenal axis suppression. The risk and extent of hypothalamic-pituitary-adrenal axis suppression is related to the corticosteroid dose, duration, time of daily administration, specific agent chosen, and route of administration. For chronic therapy, treatment with local or topical corticosteroids is warranted when available and appropriate. This includes treatment of dermatological, upper and lower airway, musculoskeletal, eye, ear, nose, throat, and bowel conditions.

Short-term use of corticosteroids has been associated with perturbance of a variety of normal functions but has not be implicated with long-term consequences. The shortterm effects include hyperglycemia; disturbances of blood pressure; edema; gastrointestinal bleeding and more serious complications; psychiatric problems; poor wound healing and increased risk of infection; and electrolyte disorders, including hypokalemia and hyperkalemia.

A recent report refutes the concept about the relative safety of short-term systemic corticosteroid use. ${ }^{15}$ A retrospective cohort study of $>1$ million subjects revealed that $21 \%$ were prescribed a short-term oral corticosteroid therapy regimen within the past year. Common reasons for use were allergies, infections of the upper respiratory tract, and spine disorders. Within $30 \mathrm{~d}$ of initiation of therapy, there was an increased risk for a variety of adverse outcomes, including an increased risk for sepsis (5.3), venous thromboembolism (3.33), and fracture (1.87). ${ }^{15}$ Although these data come from an observational study, these risks 
Table 2. Adverse Effects of Corticosteroids

\begin{tabular}{l}
\hline Hypothalamic-pituitary-adrenal axis suppression \\
Physical appearance changes: moon facies, buffalo hump, central trunk \\
obesity \\
Growth suppression \\
Hirsutism \\
Acne \\
Insomnia \\
Increased appetite \\
Hyperglycemia \\
Muscle wasting \\
Reduced bone mineral density and osteoporosis \\
Increased bruisability \\
Atrophy of skin \\
Immunosuppression \\
Cataracts \\
Glaucoma \\
Weight gain \\
Psychiatric disturbances
\end{tabular}

are alarming and require further assessment and exploration.

Normal glucocorticoid activity plays an important custodial role in metabolic and immune function. Long-term consequences of pharmacologic use of corticosteroid therapy are severe and predictable and include several problems associated with hypothalamic-pituitary-adrenal axis suppression, osteoporosis, immunosuppression, muscle wasting, and physical appearance changes. ${ }^{2}$ The scope of adverse effects and toxicities of systemic corticosteroid therapy is large, affecting nearly every organ system and metabolic process in the body. ${ }^{14}$ Many of the adverse effects are related to disruption of the normal hypothalamicpituitary-adrenal axis function. Common adverse effects are summarized in Table 2.

Patients who receive chronic therapy with systemic corticosteroids should be monitored for adverse effects. ${ }^{14}$ In adults, this includes periodic monitoring of metabolic profiles, including lipids and hematology. Bone mineral density and ophthalmologic examinations should be performed periodically. In children and adolescents, growth velocity by using a stadiometer should be monitored. ${ }^{14}$

\section{Minimizing Hypothalamic-Pituitary-Adrenal Axis Suppression}

When possible, dosing regimens for corticosteroids should be used to minimize the risk of hypothalamic-pituitary-adrenal axis suppression. The risk is associated with the daily dose of corticosteroid, number of daily doses, time of day of dosing, duration of therapy, and specific agent used (based on short, medium, or long duration of action). Although it is recognized that some conditions may exhibit a chronobiology, which suggests dosing a certain number of times a day or at a specific time of day, in general, dosing strategies should be designed to minimize hypothalamic-pituitary-adrenal axis suppression. Multiple daily doses of corticosteroids for pharmacologic effects are generally required only in acute intensive situations.

Higher daily doses of corticosteroids are associated with a higher risk for hypothalamic-pituitary-adrenal axis suppression compared with lower daily doses. When the same daily dose is used, multiple doses have a higher risk for hypothalamic-pituitary-adrenal axis suppression (eg, $10 \mathrm{mg}$ three times a day has a greater risk than $15 \mathrm{mg}$ twice a day, which has a greater risk than $30 \mathrm{mg}$ daily). Daily doses that are administered at times other than early morning have a higher risk for hypothalamic-pituitary-adrenal axis suppression (eg, $20 \mathrm{mg}$ prednisone at noon or $3 \mathrm{PM}$ has a higher risk than 8 AM dosing). Longer durations of therapy present a higher risk of hypothalamic-pituitary-adrenal axis suppression compared with shorter courses, and agents with a longer duration of action (eg, related to hypothalamic-pituitary-adrenal axis suppression) have a higher risk compared with a medium or short duration of action therapies.

\section{Tapering of Corticosteroid Therapy}

When corticosteroids are used systemically as intensive therapy or for prolonged courses, a tapering strategy is recommended to prevent signs and symptoms of adrenal insufficiency due to hypothalamic-pituitary-adrenal axis suppression. General recommendations regarding the need to consider a tapering regimen are (1) prednisone $\geq 30 \mathrm{mg}$ daily (or equivalent) for at least 2 weeks, (2) any dose of any systemic corticosteroid for at least 1 month, or (3) when signs and symptoms of hypothalamic-pituitary-adrenal axis suppression are already present. Some clinicians also use tapering to avoid an exacerbation or flare of the condition that is being treated. Although there may be examples among the hundreds of inflammatory and immune conditions for which corticosteroids are used, in general, an exacerbation that results from abrupt discontinuation of corticosteroid therapy (when appropriate) is rare.

In clinical practice, clinicians use tapering more commonly than the situations described above. There are likely multiple reasons for this decision, including concerns about hypothalamic-pituitary-adrenal axis suppression and its consequences. It is generally unnecessary to taper doses in patients who receive corticosteroids for $5-10 \mathrm{~d}$, which is among the most common regimens used for acute treatment. Unfortunately, the use of tapering in these situations can lead to longer exposure to the corticosteroid than nec- 
Table 3. Examples of Taper

1. The patient received prednisone $60 \mathrm{mg}$ daily for $3 \mathrm{wk}$ for flare of an autoimmune condition, which is now under control

Tapering strategy (duration of taper was 2 wk): Decrease by 10-mg increments every $2 \mathrm{~d}$ until $20 \mathrm{mg}$ daily is reached, then decrease by $5 \mathrm{mg}$ daily every $2 \mathrm{~d}$ until finished

2. The patient received prednisone for 3 mo for treatment of idiopathic thrombocytopenic purpura, with a current dose of $40 \mathrm{mg}$ daily and the condition is controlled

Tapering strategy (duration of taper was $7 \mathrm{wk}$ ): Decrease by $10-\mathrm{mg}$ increment weekly for $2 \mathrm{wk}(20 \mathrm{mg})$; decrease by $5 \mathrm{mg}$ weekly for $2 \mathrm{wk}(10 \mathrm{mg})$; decrease by $2.5 \mathrm{mg}$ weekly until complete

essary and the attendant risks associated with continued use.

Tapering of corticosteroids, when appropriate, is an art rather than a science and may require frequent adjustments to the tapering schedule, depending on how the patient is tolerating the taper. Although there is no one correct strategy for tapering, general recommendations based on clinical experience are provided for consideration. First, the clinical team should determine whether a rapid or slow tapering schedule is desired. Generally, shorter use of corticosteroids can be tapered fast, whereas longer durations of treatments require slower tapering. A general observation is that the duration of a taper should be $33-100 \%$ of the treatment course.

When using prednisone as an example, tapering of daily doses of $>20 \mathrm{mg}$ can be made in 10-mg increments, with adjustments made every few days to weeks, depending on the duration of the taper (Table 3 ). When a daily dose of $20 \mathrm{mg}$ daily is reached, it is useful for the patient to see the clinician for evaluation about how the tapering regimen is being tolerated. At this point, reducing the daily dose in 2.5- or 5-mg increments according to the schedule is often successful. At any point during a tapering regimen, if the patient develops signs of adrenal insufficiency, then the taper can be stopped or slowed until the patient is stable.

\section{Drug Interactions}

Drug interactions with systemic corticosteroid therapies are ubiquitous and have pharmacodynamic and pharmacokinetic foundations. Many are related to similar adverse reaction profiles with concomitant therapies, whereas pharmacokinetic interactions are often based on cytochrome P450 3A4 isoenzyme interactions. Corticosteroids are metabolic substrates for cytochrome $3 \mathrm{~A} 4$, so any agents that inhibit or induce $3 \mathrm{~A} 4$ activity will either increase or decrease corticosteroid activity. ${ }^{16}$ The National Institute for Health and Care Excellence from the United Kingdom maintains a comprehensive list of relevant interactions. ${ }^{17}$ Selected examples of interacting agents and the nature of the interaction are summarized in Table 4.
Table 4. Potential Drug Interactions With Systemic Corticosteroid Therapy

\begin{tabular}{|c|c|}
\hline ACE inhibitors & $\begin{array}{l}\text { Antagonize hypotensive action of } \\
\text { ACE-inhibitors }\end{array}$ \\
\hline Amphotericin B & Increased risk of hypokalemia \\
\hline Antidiabetic agents & $\begin{array}{l}\text { Antagonism of blood glucose lowering; } \\
\text { hyperglycemia }\end{array}$ \\
\hline Antihypertensives & Antagonism of hypotensive effects \\
\hline Carbamazepine & Increased metabolism of corticosteroid \\
\hline Cobicistat and ritonavir & Increased concentration of corticosteroid \\
\hline Estrogens & Increased concentration of corticosteroid \\
\hline Grapefruit juice & Increased concentration of corticosteroid \\
\hline Inhaled $\beta_{2}$ agonist & Increased risk of hypokalemia \\
\hline $\begin{array}{l}\text { Ketoconazole and } \\
\text { itraconazole }\end{array}$ & Increased concentration of corticosteroid \\
\hline $\begin{array}{l}\text { NSAIDs, including } \\
\text { salicylates }\end{array}$ & Increased risk for gastrointestinal bleeding \\
\hline Phenobarbital & Increased metabolism of corticosteroid \\
\hline Rifampin & Increased metabolism of corticosteroid \\
\hline Vaccines & Reduced effect of vaccines \\
\hline Warfarin & Increased or decreased effect of warfarin \\
\hline Cyclosporine & Increased concentration of cyclosporine \\
\hline \multicolumn{2}{|c|}{$\begin{array}{l}\text { Data from Reference } 16 . \\
\text { ACE }=\text { angiotensin-converting enzyme } \\
\text { NSAID }=\text { nonsteroidal anti-inflammatory drug }\end{array}$} \\
\hline
\end{tabular}

\section{Inhaled Corticosteroids}

Inhaled corticosteroids (ICS) are synthetic analogues created from the basic steroid molecule. ICS are halogenated molecules, which increases their potency. The mechanism of ICS therapies is identical to systemic agents in that the molecule must enter the nucleus of the cell and affect gene transcription. ${ }^{18}$ The first corticosteroid developed as a therapeutic aerosol was beclomethasone dipropionate in $1972 .{ }^{12}$

\section{Pharmacokinetics and Pharmacodynamics}

Formulations of ICS products have focused on several properties that improve local potency and reduced systemic exposure. ${ }^{19}$ Initial development efforts included attempts to increase anti-inflammatory activity by modifications to the steroid molecule (Fig. 2). ${ }^{11}$ For example, an additional double bond at the 1,2 position on the nucleus, and the addition of $6 \alpha$ fluoro, $6 \alpha$ methyl, or $9 \alpha$ fluoro groups on the molecule were associated with increased potency. ${ }^{18}$ Although these changes were effective, they also increased unwanted mineralocorticoid effects, which were countered by the addition of various groups at the 16 position, including $\alpha$ hydroxyl, $\alpha$ methyl, or $\beta$ methyl. The addition of ester groups was also found beneficial to reduce systemic exposure. 
Table 5. Inhaled Corticosteroid Entities and Products

\begin{tabular}{ll}
\hline \hline $\begin{array}{l}\text { Beclomethasone } \\
\text { Budesonide }\end{array}$ & $\begin{array}{l}\text { QVAR (Teva Pharmaceuticals, Frazer, PA) } \\
\text { Ciclesonide }\end{array}$ \\
$\begin{array}{l}\text { Pulmicort (AstraZeneca, Wilmington, DE) } \\
\text { Alvesco (Sunovion Pharmaceuticals, } \\
\text { Marlborough, MA) } \\
\text { Fluticasone furoate }\end{array}$ & $\begin{array}{l}\text { *Aerospan (Mylan Pharmaceuticals) } \\
\text { Triangle Park, NC) }\end{array}$ \\
$\begin{array}{l}\text { Fluticasone propionate } \\
\text { Mometasone }\end{array}$ & $\begin{array}{l}\text { Flovent (GlaxoSmithKline) } \\
\text { Triamcinolone }\end{array}$ \\
& $\begin{array}{l}\text { Asmanex (Merck, Whitehouse Station, NJ) } \\
\text { * Product discontinued. }\end{array}$ \\
\hline
\end{tabular}

Individual ICS molecules have specific and unique properties that affect their formulation and use. In terms of pharmacology, they differ in physicochemical properties, selectivity for the glucocorticoid receptor, potency, and pharmacokinetics. The impact of the pharmacologic features on the efficacy and safety of various ICS products has been under considerable debate during the past 2 decades. In fact, for the clinician, the interaction and mix of positive and negative attributes for specific molecules present challenges in determining if an individual agent offers significant advantages in either efficacy or safety.

ICS agents are effective in controlling asthma when dosed either once or twice daily, depending on the specific agent and asthma severity. Intermittent use may be beneficial for some patients but is not a standard of care practice in the U.S. Historically, ICS therapy was thought to have a delayed onset of effect when used for asthma. Analysis of data available with currently used potent ICS therapies indicates that a significant therapeutic benefit is demonstrated within 1-2 weeks of initiation. ${ }^{20}$

\section{Receptor Affinity, Lipophilicity, and Bioavailability}

Pharmaceutical development has focused on increasing lipophilicity and reducing oral bioavailability of ICS products. Efforts have also been directed at improving receptor affinity and prolonging binding at pulmonary receptors. Improvements in inhaler technology have benefited the development of ICS products, including ancillary devices that can improve pulmonary delivery and reduce extrapulmonary exposure. The result has been new agents with improved receptor selectivity, potency, and targeting of the lung with reduced oral bioavailability and high systemic clearance. As of 2017, there are 8 corticosteroid agents available for inhalation (Table 5). Among the available agents, beclomethasone dipropionate and ciclesonide are prodrugs that are converted to their active forms by esterases in the lung and other tissues. ${ }^{12}$
One characteristic of ICS that is often highlighted is the receptor binding affinity, with the presumption that higher affinity is desirable. Corticosteroid receptors in the lungs are similar to receptors throughout the body; therefore, a high affinity for corticosteroid receptors in the lung would also be exhibited at systemic receptors. As a result, a high affinity for systemic receptors would be associated with a greater risk for systemic effects that are undesirable. A differentiating feature of ICS products would be a high receptor binding affinity with reduced systemic bioavailability. ${ }^{21}$ Absorption across the lung and absorption through the gastrointestinal tract both contribute to systemic bioavailability; thus, the problem remains complex, depending on the extent of absorption at the 2 sites. In one older study, an ICS delivered through a dry powder inhaler (DPI) resulted in systemic concentrations attributed to lung absorption (32\%) and gastrointestinal absorption (6\%). ${ }^{22}$ When the same drug and dose were administered via a pressurized metered-dose inhaler (pMDI), $15 \%$ of the attributed concentration came from the lung and $11 \%$ from gastrointestinal tract absorption. ${ }^{22}$

Fluticasone propionate has a high receptor affinity, but there is evidence of systemic effects that are causing hypothalamic-pituitary-adrenal axis suppression at high does. Fluticasone propionate also has high lipophilicity but does not conjugate with fatty acids, which would allow more residence time at the pulmonary receptor. Mometasone exhibits high receptor binding affinity and protein binding; it is lipophilic and undergoes high first-pass metabolism. However, its systemic effects may be influenced by active metabolites. Budesonide does form fatty acid conjugates, but, because of lower lipophilicity, pulmonary retention may be lower. ${ }^{6}$

Ciclesonide is an ICS that claims activation in the lung, high pulmonary deposition, and low systemic exposure. This molecule is purported to have a high affinity for the glucocorticoid receptor, high lipophilicity and fatty acid conjugation, and high protein binding and systemic clearance. ${ }^{6}$ In comparative studies with other ICS, the results showed improvement for various efficacy and safety outcomes and patient preference. ${ }^{23}$ However, ciclesonide does not enjoy a significant advantage in the marketplace, which suggests that its characteristics are also more important from a marketing perspective and are more difficult to differentiate clinically. A Cochrane review regarding ciclesonide versus other ICS therapies did not find significant advantages of this agent. ${ }^{24}$

In general, pharmacodynamic and pharmacokinetic properties of ICS influence efficacy and safety; however, because there are numerous characteristics of individual agents that influence these properties, the overall impact is sometimes unclear and often controversial. ${ }^{6}$ The optimal ICS would be an agent that exhibits significant local and sustained effects in the airways and minimal systemic ef- 
Table 6. Characteristics for an Ideal Inhaled Corticosteroid Agent

\begin{tabular}{|c|c|c|}
\hline Parameter of Interest & Efficacy & Safety \\
\hline Bioavailability & High pulmonary desirable & Low systemic desirable \\
\hline Delivery device & $\begin{array}{l}\text { Particle size optimized to be respirable and deposited; } \\
\text { high fraction delivered to lung }\end{array}$ & Maximize lung delivery; minimize extrapulmonary deposition \\
\hline Receptor-binding affinity & High & Low \\
\hline Protein binding & $\%$ protein bound does not influence efficacy significantly & High protein binding may reduce systemic effects \\
\hline Clearance & Effect unclear & Rapid metabolism desirable \\
\hline Half-life & Longer half-life is desirable & Longer increases risk \\
\hline Prodrug formulations & Hydrolysis and local activity & Inactive parent and metabolic products preferred \\
\hline Lipophilicity & Feature is associated with longer retention time & $\begin{array}{l}\text { Unclear; feature is associated with lower serum concentrations } \\
\text { but greater distribution }\end{array}$ \\
\hline
\end{tabular}

fects based on limited bioavailability and rapid systemic clearance..$^{25,26}$ The preferred therapy would exert selective topical effects, with minimal systemic absorption or rapid inactivation after absorption. ${ }^{16}$ Various pharmacokinetic and pharmacodynamic features of ICS that have been identified as having a role in the overall efficacy and safety profile are summarized in Table 6 .

Because of the numerous properties and characteristics that influence ICS actions and safety, it is difficult to measure the influence of a single property because each can have disparate effects. For example, the receptor binding affinity of available ICS agents varies by $10-100$-fold, and oral bioavailability by 20 -fold. However, protein binding of available agents is relatively consistent, ranging from $71 \%$ to $99 \%$, lipophilicity varies $\sim 4$-fold, and halflives are generally $\leq 5 \mathrm{~h}$, with the exception of fluticasone propionate at $\sim 14 \mathrm{~h}$. Perhaps, because of the similarities or the numerous differences among agents, no single agent seems to have significant advantages or confers additional risks in clinical practice. Of note, the inhalational device used to administer the therapeutic agent also has a significant influence on local and systemic effects because these characteristics can vary between devices.

\section{Potency}

An advantage of ICS is their high potency, which allows occupancy of a glucocorticoid receptor at a lower dose compared with less-potent agents. The potency of topical corticosteroids varies, depending on the specific agent, and characterizing the relative potency among available therapies is challenging and imperfect. The relatively flat dose-response curve of ICS also hinders estimates of relative potency among available agents. ${ }^{27}$ Historically, the skin vasoconstrictor test has been used to describe relative potency among topical therapies, although this has numerous limitations when used to evaluate inhaled therapies. ${ }^{28}$ Potency has also been reported based on the glucocorticoid receptor binding affinity, although it is recognized that numerous other factors also influence potency. ${ }^{29}$ More recently, exhaled nitric oxide concentrations has been used as a tool to evaluate anti-inflammatory effects. Although the fraction of exhaled nitric oxide shows promise in assessing relative potency, it is most commonly used to assess asthma control. ${ }^{7}$

The potency of an individual agent is influenced by multiple factors, including the affinity of binding to the glucocorticoid receptor. Based on these criteria, one group of investigators suggests that the relative potency of available agents (from high to low) is fluticasone furoate $>$ mometasone $>$ fluticasone propionate $>$ beclomethasone $>$ ciclesonide $>$ budesonide $>$ triamcinolone $>$ flunisolide. ${ }^{9}$ However, there is not consensus regarding relative potency. Other investigators suggest that the inhalational device used to deliver the ICS also contributes to relative potency. ${ }^{7}$ By using this method, the relative potency is beclomethasone $(\mathrm{pMDI})=$ ciclesonide $(\mathrm{pMDI})>$ fluticasone propionate $(\mathrm{pMDI})>$ fluticasone propionate $(\mathrm{DPI})>$ mometasone $(\mathrm{DPI})$ $>$ flunisolide $(\mathrm{pMDI})>$ budesonide $(\mathrm{DPI})>$ budesonide (nebulizer). ${ }^{7}$

\section{Dose-Response}

The dose-response to ICS is relatively flat, with the majority of effect exhibited at the lower end of the dose range. ${ }^{30}$ The lack of a linear dose-response has been challenging for ICS. The dose-response occurs in a log-dose linear fashion, so that doubling of the dose often does not result in significant improvements in the outcome parameter. ${ }^{7}$ In general, patients benefit from low doses, but the incremental benefit of increasing doses has been difficult to assess. ${ }^{12}$ There has been greater success in evaluating a dose-response between low and medium doses. In fact, in some clinical trials, a dose-response relationship could not be established, and, in others, differences in the doseresponse between agents have been difficult to determine. ${ }^{31}$ There seems to be a clearer dose-response risk related to adverse effects, including hypothalamic-pituitary-adrenal 


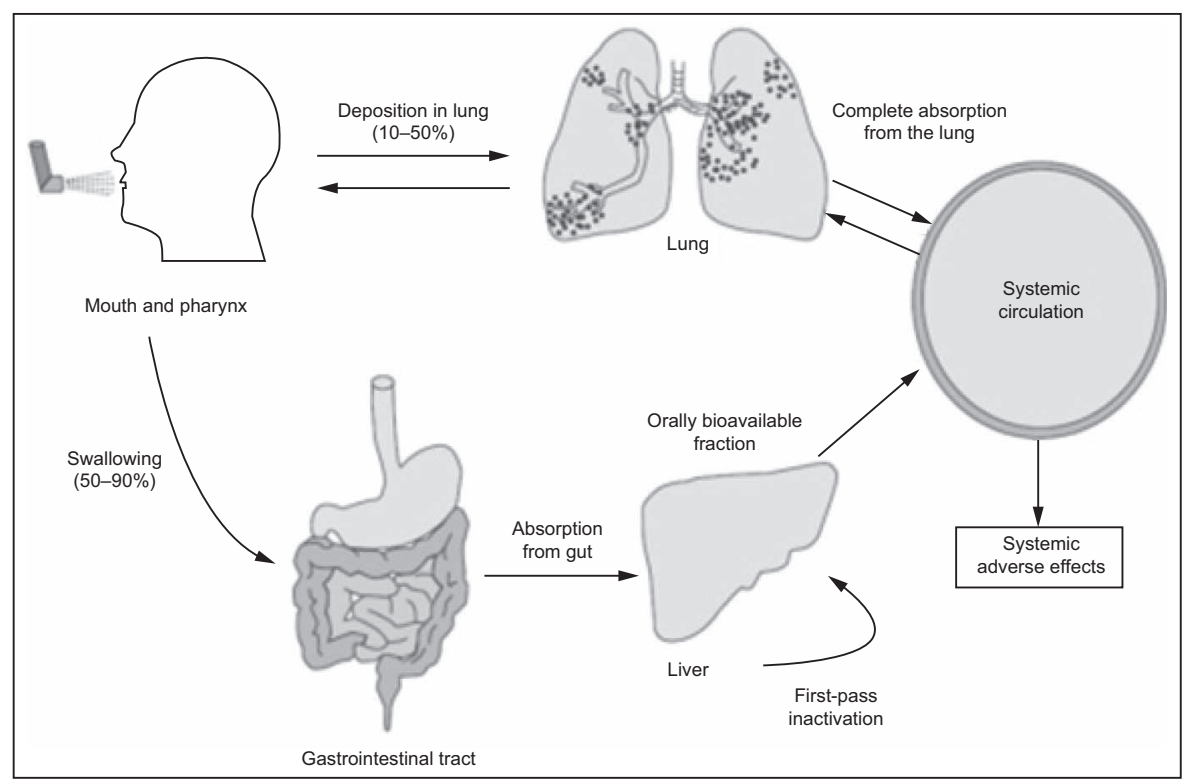

Fig. 3. Schematic of the progress of an inhaled corticosteroid. From Reference 6, with permission.

axis suppression, with a steep increase associated with higher doses. ${ }^{9}$ The dose-response relationship is further complicated by the fact that it may differ based on the parameter assessed, including spirometry, symptom control, exacerbations, and various inflammatory markers. One sensitive measure, bronchial hyper-responsiveness, may be more sensitive than other parameters. ${ }^{32}$

\section{Therapeutic Index}

The therapeutic index of a molecule describes the relationship between efficacy and safety, or the risks for adverse reactions. The therapeutic index is typically a ratio of doses associated with these 2 parameters, with a higher therapeutic index considered desirable. Properties associated with a higher therapeutic index include increased potency, long retention in lung, reduced oral bioavailability, and high systemic clearance. ${ }^{29}$ For ICS products, the therapeutic index varies according to the dose, with the most desirable index associated with lower doses. ${ }^{12}$ The therapeutic index for ICS decreases as the dose increases. However, the therapeutic index for ICS products is favorable when compared with the therapeutic index for systemic corticosteroids, for example, prednisone. According to one report, inhaled agents with the highest therapeutic index include the 2 fluticasone salts, mometasone, and ciclesonide, with lower therapeutic indexes for beclomethasone, triamcinolone, and budesonide. ${ }^{12}$

\section{Disposition}

The disposition of an inhaled dose of ICS has been described (Fig. 3). ${ }^{6}$ A fraction of the dose reaches the airway, where it is deposited. The medication deposited in the airway is largely responsible for the therapeutic effect for lung disease. A portion of that dose will reach the systemic circulation through absorption, depending on the molecule's characteristics. Another portion of the inhaled dose either deposits in the oropharyngeal region or is swallowed. Based on the inhalation device, 40-90\% of the dose may be deposited in the oropharynx or swallowed. ${ }^{9}$ Part of that dose is also absorbed into the systemic circulation. The absorbed portion of an inhaled dose (from the lungs or the gastrointestinal tract) passes through the liver, where a portion is removed by first-pass metabolism. The remainder of the dose stays in the systemic circulation until it is cleared by subsequent metabolism in the liver or through other mechanisms.

The use of ancillary delivery devices (eg, spacers and holding chamber) can have variable effects on drug disposition. In general, these devices increase the fraction of the dose deposited in the airway and reduce the fraction of the dose that is deposited in the oropharynx or that is swallowed. This can impact systemic absorption, either through pulmonary or extrapulmonary tissues, which will affect overall bioavailability. Maneuvers such as mouth rinsing and spitting will reduce extrapulmonary absorption of ICS doses and reduce the systemic exposure.

\section{Adverse Drug Reactions and Side Effects}

Concerns about adverse effects from ICS therapies can be a barrier to adherence. There are significant barriers to adherence with ICS therapies. ${ }^{26,28,29}$ There are adverse effects associated with therapy; however, many concerns expressed by patients are not accurate and reflect myths 
about the risk from these therapies. The most common local effects of ICS are oral candidiasis and dysphonia. ${ }^{16,31}$

Throat cultures can often be positive for Candida, although $<5 \%$ of patients experience symptoms. The risk for oropharyngeal candidiasis can be reduced with spacer and/or holding chamber use and mouth rinsing after inhaling doses. Dysphonia is dose related and more commonly detected in patients who require strong use of their voice, including singers or public speakers. Holding chambers and mouth rinsing may also limit this problem. ${ }^{31}$

The risk/benefit ratio for ICS is significantly better compared with systemic corticosteroids, but risks are present with long-term use and are dose related. ${ }^{31}$ ICS can affect hypothalamic-pituitary-adrenal axis function, bone metabolism, and endocrine and hematologic function. There have also been concerns about associations with cataracts and thinning of the skin. There are anecdotal and case reports regarding these effects, and there does seem to be a dosedependent relationship. The risk for hypothalamic-pituitary-adrenal axis suppression is reported to increase at relative doses of beclomethasone of $\geq 800 \mu \mathrm{g} .{ }^{33}$ However, results from studies are inconsistent, and the association with ICS has been difficult to determine. It is clear that the risk of these adverse reactions and toxicities is significantly less than the association with systemic therapy.

Growth suppression in children and adolescents does occur with ICS therapy and is dose related. The effect is temporary and not cumulative with continued use. Results of studies indicate that children treated with ICS can experience transient decreases in growth velocity but the cumulative effect on adult height is approximately a half inch. ${ }^{9,34,35}$ Children and adolescents treated with ICS should be monitored periodically for growth rates. ICS effects on bone mineral density are equivocal and may depend on the population studied. There is no evidence of an effect in children and adolescents, ${ }^{9}$ whereas adult studies yielded variable results. ${ }^{7}$ Again, if an effect is present, it seems to be dose dependent.

Although ICS is an effective therapy to reduce the risk for exacerbations (when combined with long-acting $\beta_{2}$ agonists), their use is also associated with an increased risk of pneumonia. ${ }^{36}$ Evidence concerning an increased risk of respiratory tract infections in patients with COPD who were treated with ICS emerged several years ago and has been confirmed in various studies. ${ }^{37,38}$ One large cohort study followed up $>160,000$ subjects with COPD for $>5 \mathrm{y}$ and determined a relative risk of pneumonia of 1.69 when ICS were used. ${ }^{37}$ The risk continued during the period of use and gradually declined over 6 months after discontinuation. The basis for an increased risk for pneumonia is unclear, especially in light of the benefit in exacerbation reduction. There does not seem to be an increased risk for mortality associated with pneumonia in users of ICS. ${ }^{38}$
Table 7. Cytochrome P450 3A4 Inhibitors That May Increase the Risk of Adverse Drug Reactions and Toxicities From Inhaled Corticosteroid Therapies

\author{
Itraconazole \\ Ketoconazole \\ Ritonavir \\ Grapefruit juice \\ Clarithromycin \\ Calcium channel blockers
}

Cobicistat

Patients with COPD who are treated with ICS therapy should be monitored for pneumonia.

To date, the increased risk for respiratory infections and pneumonia has been reported in patients with COPD. A more recent study, by using a quasi-cohort design, concluded that subjects with asthma were at greater risk for pneumonia if they used ICS therapy. ${ }^{39}$ The overall risk associated with current ICS use was 1.83. The relative risk was dose related (1.6 for low dose and 1.96 for high dose), and higher for budesonide and fluticasone compared with other agents (2.67 and 1.93, respectively). The study design has a number of limitations, but this finding warrants further investigation.

\section{Drug Interactions}

As noted, the potential for drug interactions with systemic corticosteroid therapy is significant. Similarly, there is a risk for drug interactions with ICS and other therapies. Most ICS interactions are related to pharmacokinetic interactions that involve metabolism. ICS metabolism occurs via cytochrome P450 3A4 CYP3A4 biotransformation. ${ }^{19}$ The $3 \mathrm{~A} 4$ pathway is inducible by corticosteroids and represents a source of drug interactions. ${ }^{16}$ The most significant interactions have been reported with strong CPY3A4 inhibitors, such as ritonavir, ketoconazole, and itraconazole; however, there can also be problems with other therapies (Table 7). When these agents are used with ICS therapies, patients are at risk for clinical adrenal suppression and Cushing syndrome. There are numerous case reports that involved ritonavir and ICS, which cause these effects). ${ }^{40}$ More recently, there are reports of similar interactions with budesonide, fluticasone, and mometasone when used with cobicistat. ${ }^{41}$ The $3 \mathrm{~A} 4$ pathway is common for many ICS, including budesonide and fluticasone. Each of the other ICS products, including beclomethasone, ciclesonide, flunisolide, mometasone, and triamcinolone, is also a substrate for $3 \mathrm{~A} 4$, but the least affected may be beclomethasone. Beclomethasone uses a CPY3A4 pathway in its metabolism to a more active metabolite; however, the major path for inactivation is through hydrolysis 
by esterases. As a result, beclomethasone is the ICS of choice for patients who use a strong CYP3A4 inhibitor. ${ }^{42}$

\section{Clinical Applications in Lung Disease}

Corticosteroids have numerous uses based on pleotropic effects on inflammation and immune function. They can be used for severe life-threatening hypersensitivity reactions and to treat significant inflammatory responses. Longterm use is associated with significant consequences associated with excessive glucocorticoid effects on organs and metabolic function. Topical therapies offer the advantage of localized treatment while minimizing systemic risks.

\section{Asthma}

ICS are the cornerstone of chronic asthma management. These agents are the most effective therapy in maintaining asthma control through anti-inflammatory effects on the airway. ICS therapy reduces morbidity and mortality from asthma. ${ }^{7}$ ICS are the preferred chronic therapy for asthma, independent of severity or patient age. Adverse effects of ICS are dose dependent, and the patient should be maintained on the lowest effective dose necessary to control asthma and be monitored for potential adverse effects. Systemic corticosteroids represent an important component of acute asthma exacerbation management. Doses of $0.5-2 \mathrm{mg} / \mathrm{kg} / \mathrm{d}$ are appropriate and the duration of therapy is typically less than $10 \mathrm{~d}$.

\section{COPD}

ICS therapy has a more-limited role in the management of COPD. In patients with more-severe air-flow limitation, characterized by an $\mathrm{FEV}_{1}$ of $<0.50$, and who experience frequent exacerbations despite treatment with long-acting bronchodilator therapy, ICS is warranted. ${ }^{43}$ ICS should be used in combination with a long-acting bronchodilator for COPD. There is an increased risk for respiratory tract infections, including pneumonia, in patients with COPD who were treated with ICS. ${ }^{44}$ Systemic corticosteroids have a role in exacerbations of COPD. Although higher doses have been used historically, a regimen of $40 \mathrm{mg}$ of prednisone daily $(\sim 0.5-1 \mathrm{mg} / \mathrm{kg} / \mathrm{d})$ is effective. A 5 -d course of therapy was shown to be non-inferior to 2 wk. ${ }^{45}$

\section{Summary}

Corticosteroids represent important therapies for numerous acute conditions and chronic diseases based on their broad anti-inflammatory and immunosuppressant effects. Corticosteroid therapy can be life-saving in serious and severe medical conditions. Use of these therapies are associated with significant consequences and adverse effects, especially when prolonged therapy is needed. There are strategies that can be used to minimize these risks, but some risks are often unavoidable. Topical use of corticosteroids, including inhalation, can be used to target specific organs for treatment.

\section{REFERENCES}

1. Gupta P, Bhatia V. Corticosteroid physiology and principles of therapy. Indian J Pediatr 2008;75(10):1039-1044.

2. Shaikh S, Verma H, Yadav M, Jauhari M, Bullangowda J, Applications of steroid in clinical practice: a review. ISRN Anesthesiol 2012, vol. 2012, Article ID 985495, 11 pages, 2012. doi:10.5402/ 2012/985495

3. Becker DE. Basic and clinical pharmacology of glucocorticosteroids. Anesth Prog 2013;60(1):25-31; quiz 32.

4. Annane D. Adrenal insufficiency in sepsis. Curr Pharm Des 2008; 14(19): 1882-1886.

5. Taylor DR, Hancox RJ. Interactions between corticosteroids and beta agonists. Thorax 2000;55:595-602.

6. Derendorf H, Nave R, Drollmann A, Cerasoli F, Wurst W. Relevance of pharmacokinetics and pharmacodynamics of inhaled corticosteroids to asthma. Eur Respir J 2006;28(5):1042-1050.

7. Raissy HH, Kelly HW, Harkins M, Szefler SJ. Inhaled corticosteroids in lung diseases. Am J Respir Crit Care Med 2013;187(8):798803.

8. Barnes PJ. How Do Corticosteroids Work in Asthma? Ann Intern Med 2003;139(5 Pt 1):359-370.

9. Ye Q, He XO, D'Urzo A. A review on the safety and efficacy of inhaled corticosteroids in the management of asthma. Pulm Ther 2017;3(1):1-18.

10. Ericson-Neilsen W, Kaye AD. Steroids: pharmacology, complications, and practice delivery issues. Ochsner J 2014;14(2):203-207.

11. Moss GP. Nomenclature of steroids. Pure Appl Chem 1989;61(10): 1783-1822.

12. Daley-Yates PT. Inhaled corticosteroids: potency, dose equivalence and therapeutic index. Br J Clin Pharmacol 2015;80(3):372-380.

13. Swartz SL, Dluhy RG. Corticosteroids: clinical pharmacology and therapeutic use. Drugs 1978;16(3):238-255.

14. Liu D, Ahmet A, Ward L, Krishnamoorthy P, Mandelcorn ED, Leigh $\mathrm{R}$, et al. A practical guide to the monitoring and management of the complications of systemic corticosteroid therapy. Allergy Asthma Clin Immunol 2013;9(1):30-37.

15. Waljee AK, Rogers MA, Lin P, Singal AG, Stein JD, Marks RM, et al. Short term use of oral corticosteroids and related harms among adults in the United States: population based cohort study. BMJ 2017;357:j1415.

16. Lipworth BJ. Clinical pharmacology of corticosteroids in bronchial asthma. Pharmacol Ther 1993;58(2):173-209.

17. National Institute for Health and Care Excellence (2017). List of Drug Interactions: Corticosteroids. Evidence Search. Accessed 16 May 2017.

18. Johnson M. Development of fluticasone propionate and comparison with other inhaled corticosteroids. J Allergy Clin Immunol 1998; 101(4 Pt 2):S434-S439.

19. Brattsand R. Development of inhaled steroids: past, present and prospects. In: Dalby RN, Byron PR, Peart J, Farr SJ, editors. Respiratory Drug Delivery. Richmond, VA: Virginia Commonwealth University; 2002:1-14.

20. Phillips K, Oborne J, Lewis S, Harrison TW, Tattersfield AE. Time course of action of two inhaled corticosteroids, fluticasone propionate and budesonide. Thorax 2004;59(1):26-30. 
21. Yeo SH, Aggarwal B, Shantakumar S, Mulgirigama A, Daley-Yates P. Efficacy and safety of inhaled corticosteroids relative to fluticasone propionate: a systematic review of randomized controlled trials in asthma. Expert Rev Respir Med 2017;11(10):763-778.

22. Thorsson L, Edsbäcker S, Conradson TB. Lung deposition of budesonide from Turbuhaler is twice that from a pressurized metered-dose inhaler P-MDI. Eur Respir J 1994;7(10):1839-1844.

23. van der Molen T, Kocks JW. The efficacy and safety of inhaled corticosteroids: are we ignoring the potential advantages of ciclesonide? NPJ Prim Care Respir Med 2014;24:14013.

24. Kramer S, Rottier BL, Scholten RJ, Boluyt N. Ciclesonide versus other inhaled corticosteroids for chronic asthma in children. Cochrane Database Syst Rev 2013;(2):CD010352.

25. Derendorf H, Hochhaus G, Meibohm B, Möllmann H, Barth J. Pharmacokinetics and pharmacodynamics of inhaled corticosteroids. J Allergy Clin Immunol 1998;101(4 Pt 2):S440-S446.

26. Sobande PO, Kercsmar CM. Inhaled corticosteroids in asthma management. Respir Care 2008;53(5):625-633; discussion 633-634.

27. García-Arieta A. Sensitive studies with a significant dose-response curve for inhaled corticosteroids to investigate equivalent relative potency are feasible. Br J Clin Pharmacol 2011;72(5):832-833; author reply 834-835.

28. Colice GL. Comparing inhaled corticosteroids. Respir Care 2000; 45(7):846-853.

29. Kelly HW. Comparison of inhaled corticosteroids: an update. Ann Pharmacother 2009;43(3):519-527.

30. Zitt MJ. Advances in inhaled corticosteroid pharmacology. Allergy Asthma Proc 2007;28(2):114-124.

31. Geddes DM. Inhaled corticosteroids: benefits and risks. Thorax 1992; 47(6):404-407.

32. Currie GP, Fowler SJ, Lipworth BJ. Dose response of inhaled corticosteroids on bronchial hyperresponsiveness: a meta-analysis. Ann Allergy Asthma Immunol 2003;90(2):194-198.

33. Martin RJ, Szefler SJ, Chinchilli VM, Kraft M, Dolovich M, Boushey HA, et al. Systemic effect comparisons of six inhaled corticosteroid preparations. Am J Respir Crit Care Med 2002;165(10):1377-1383.

34. Kelly HW, Sternberg AL, Lescher R, Fuhlbrigge AL, Williams P, Zeiger RS, et al; CAMP Research Goup. Effect of inhaled glucocorticoids in childhood on adult height. N Engl J Med 2012;367(10): 904-912.
35. Loke YK, Blanco P, Thavarajah M, Wilson AM. Impact of inhaled corticosteroids on growth in children with asthma: Systematic review and meta-analysis. PLoS One 2015;10(7):e0133428.

36. Bourbeau J, Aaron SD, Barnes NC, Davis KJ, Lacasse Y, Nadeau G. Evaluating the risk of pneumonia with inhaled corticosteroids in COPD: Retrospective database studies have their limitations SA. Respir Med 2017;123:94-97.

37. Suissa S, Patenaude V, Lapi F, Ernst P. Inhaled corticosteroids in COPD and the risk of serious pneumonia. Thorax 2013;68(11):10291036.

38. Kew KM, Seniukovich A. Inhaled steroids and risk of pneumonia for chronic obstructive pulmonary disease. Cochrane Database Syst Rev 2014;(3):CD010115

39. Qian CJ, Coulombe J, Suissa S, Ernst P. Pneumonia risk in asthma patients using inhaled corticosteroids: a quasi-cohort study. Br J Clin Pharmacol 2017;83(9):2077-2086.

40. Saberi P, Phengrasamy T, Nguyen DP. Inhaled corticosteroid use in HIV-positive individuals taking protease inhibitors: a review of pharmacokinetics, case reports and clinical management. HIV Med 2013; 14(9):519-529.

41. Drummond MB, Kunisaki KM, Huang L. Obstructive lung diseases in HIV: A clinical review and identification of key future research needs. Semin Respir Crit Care Med 2016;37(2):277-288

42. Daveluy A, Raignoux C, Miremont-Salamé G, Girodet PO, Moore N, Haramburu F, Molimard M. Drug interactions between inhaled corticosteroids and enzymatic inhibitors. Eur J Clin Pharmacol 2009; 65(7):743-745

43. GOLD Science Committee. Global Initiative for Chronic Obstructive Lung Disease. 2018 ed. Global Initiative for Chronic Obstructive Lung Disease, Inc; 2018. http://copdgold.org. Accessed December 31, 2017.

44. Babu KS, Kastelik JA, Morjaria JB. Inhaled corticosteroids in chronic obstructive pulmonary disease: a pro-con perspective. $\mathrm{Br} \mathrm{J}$ Clin Pharmacol 2014;78(2):282-300.

45. Leuppi JD, Schuetz P, Bingisser R, Bodmer M, Briel M, Drescher T, et al. Short-term vs conventional glucocorticoid therapy in acute exacerbations of chronic obstructive pulmonary disease: the REDUCE randomized clinical trial. JAMA 2013;309(21):2223-2231.

\section{Discussion}

Peters: I would like to follow up on your comment about the use of depo (long-acting) steroids for acute severe asthma, I want to mention that there was a study in which, in subjects with asthma who were steroid-dependent, they put tiny bits of phenobarbital in the steroid and measured it in the urine. This study showed that up to one third of the subjects with asthma did not consistently take their oral corticosteroids. The new Global Initiative for Asthma 2017 guidelines $^{1}$ state that, after an exacerbation, physicians might consider intramuscular injections of steroids if there is a high risk of non- adherence with oral medications based on the high risk of relapse after exacerbations. In my experience, one of the most difficult groups of patients with asthma to take care of are the ones with very low small airways parameters on their pulmonary function tests. They have markedly reduced $\mathrm{FEF}_{25-75}$ and often don't seem to respond well to inhaled steroids. It is believed in some asthma centers that inhaled steroids with a greater fineparticle fraction actually have additional benefit. It's not uncommon that they place patients on a standard inhaled steroid and add a second one with a higher fine-particle fraction. I'm curious as to your thoughts and the group's thoughts because this is not an uncommon clinical scenario.

Williams: It's a good question. So, particle size is one of those features out of many that we see as maybe conferring additional benefit and I appreciate your clinical experience in terms of patients who did or didn't respond when you make that kind of change. In my view, I think it's worthy of exploration. I've heard that referred to when describing benefits of using a product like nebulized budesonide, for instance, and there may be other examples. I'm not aware of good clinical data that consistently support that it might work for a large population of patients. There's a growing body of 
anecdotal information in which people make observations and say, "it seems like this worked," so I'm receptive to that.

Mann: Beclomethasone dipropionate has been known to have a very small particle size and has been used at least anecdotally, to my knowledge, for treating patients with asthma and with very small airway disease like you talked about. I don't know if there are literature or actual studies around beclomethasone dipropionate added to an existing ICS regimen but that would be an inhaled steroid to look at.

*Newhouse: There's literature going back more than 15 years. Bill Busse showed, in a very nice study, ${ }^{2}$ that you needed half as much of the ultrafine beclomethasone dipropionate (mass median aerodynamic diameter of $1.1 \mu \mathrm{m}$ ) to control asthma than previously with the larger particles (mass median aerodynamic diameter of 3-4 $\mu \mathrm{m})$. The other thing I'd like to point out is that there's a huge problem with DPIs because they tend to be large particles, you have to inhale with a very high flow and you end up with approximately three fourths of it at the back of your throat and around your larynx. That has never made much sense to me. Getting back to my pet topic, having been very involved in the development of the AeroChamber (Aerogen, Dublin, Ireland), valved holding chambers should always be used, particularly in children, but I think in everyone, when you're using ICS. Because you reduce the upper respiratory tract dose by $\sim 90 \%$, so that speaks to what you said about reducing the systemic effect of steroids and targeting them to the lower respiratory tract.

Williams: In the area of improvements in delivery systems, I concur. My view is that we've made significant advancements, in that inhalation devices are now much better than they were 15 years ago, including particle sizes, and we've seen that with the newer beclomethasone dipropionate products with the same outcomes with a lower dose. We continue to improve with DPIs. I think there's an effort to minimize the required inspiratory flows and to maximize the dispersibility of those into small particles. I think we've incrementally gotten better in that area. One of the things I'm looking forward to in the discussion about spacers and holding chambers later is that I think that, in many ways, today we extrapolate data about the use of ancillary devices from older devices and not so much from the ones being currently used.

Wechsler: In terms of particle sizes, the beclomethasone dipropionate and ciclesonide both have similar particle sizes, of $\sim 1 \mu \mathrm{m}$. The newer ICS, the fluticasone HFA is not much bigger. It's about half the size of the previous fluticasone in the DPI, and mometasone also has a relatively small particle size, of 2-3 $\mu \mathrm{m}$. I think a lot of it has to do with deposition and the device and the inspiratory effort that the patient can generate. The data are a little bit controversial, and while some studies have shown greater efficacy, there hasn't been a really good study done that shows significant differences in terms of efficacy or outcomes that are important to patients: no significant differences in exacerbations or lung function. There have been deposition studies that show that the drugs go a little bit further but that has not been reflected in larger clinical trials. Smaller trials have actually failed to demonstrate a significant difference.

MacIntyre: Maybe you can clarify this for me, I've heard the strategy of using 2 inhaled steroids, one with a small particle and one with a bigger particle. Does that make any sense?

*Newhouse: No, I don't think it does, because you've got a geometric SD, which takes care of that. You get distribution throughout the airway, but, by using smaller particles and, again, particularly in children, you have a greater likelihood of reaching the small airways and asthma is a disease of the whole lung, not just the larger airways.

Pleasants: Just to change it up a little bit, probably $25 \%$ of our adult patients with asthma (and patients with COPD) have diabetes; a lower percentage have asthma and heart failure. I know you use methylprednisone in these patients. Dexamethasone does have notably lower mineralocorticoid effects, and I have used it clinically in patients with profound heart failure. So I'm wondering about the group's perspective or opinion of using dexamethasone instead of prednisone or methylprednisone in that situation?

Williams: Roy, my view is, it seems to me that when oral corticosteroids are used in specific diseases, it's a historical perspective. This is the drug we used before so that's why we continue to do it. I can definitely see some theoretical advantages to using dexamethasone. There may be fewer effects in one area, but I do worry about its prolonged action on the hypothalamic-pituitary-adrenal axis, and I personally haven't seen a well-conducted study to evaluate whether that would be beneficial; maybe for a shorter period of time. It would be a good study.

Pleasants: I think it has been studied in the short term in asthma, I'm not sure about COPD, but, again, it does have less mineralocorticoid effect, and I think there are some benefits. But you have to be careful about the long half-life and greater potency and so forth.

Wechsler: At National Jewish, we do steroid pharmacokinetics and pharmacodynamics studies; I don't think they are done anywhere else in the country, but we get a lot of patients with primarily asthma but also COPD who may be refractory to specific systemic corticosteroids. We have been 
able to identify patients who may respond better to one systemic corticosteroid versus another. It can be beneficial. There are probably some differences in a given individual in terms of responsiveness. Two other comments. One is that there are also steroid pharmacogenetic studies that have been done by Kalen Tantisira among others, ${ }^{3-6}$ and those have demonstrated that there may be pharmacogenetic differences across individuals, which may suggest that there are differences in terms of responsiveness to corticosteroids. The second point is there was a Severe Asthma Research Program study ${ }^{7}$ in which subjects with severe asthma were given intramuscular injections of triamcinolone to try to maximize beneficial effects. There were no significant differences a month or so after they were given intramuscular triamcinolone to try to mitigate the effects of non-adherence to systemic steroids.

Donohue: Dennis, I had 2 comments on inhaled steroids. I don't work much with inhaled steroids any more except in combinations, but we did show one outcome with dose-response and that was the ability to wean off oral steroids when we used high-dose fluticasone. Remember those studies that did show an outcome effect in which the higher-than-recommended doses were more likely to reduce oral corticosteroids. $^{8}$

Williams: That's a different way to look at dose-response.

Donohue: Yes, it's a different kind of outcome. Even though there's an enormous debate as you mentioned about particle size and pharmacology of these particles and even people who have argued that you shouldn't put a combination of an inhaled steroid that needs to be small to maximize the effects on receptors versus $\beta$ agonist, which needs to be a little bit bigger because the receptors are more distributed in the large airway. My ques- tion is that, for many years in status asthmaticus, we operated under the assumption that there was steroid downregulation intolerance. Hence, we used industrial strength steroids, and Jay [Peters] is the world's expert in this, like $125 \mathrm{mg}$ methylprednisolone 4 times a day, and that was based on a blood level of cortisol, which is the maximum stimulated adrenal, but we don't talk about that much any more. What are your thoughts about the downregulation effects? Should that alter our clinical thinking when a patient comes in the hospital?

Williams: The dose of corticosteroid required for an exacerbation has certainly evolved over time, and our strategies vary, depending on whether we are treating asthma or COPD exacerbations. There was the big Veterans Administration study 9 with methylprednisolone that set that standard for COPD treatment, starting at $125 \mathrm{mg}$ every $6 \mathrm{~h}$. However, since that time, there is evidence that much lower doses are effective. ${ }^{10}$ Also, results of the REDUCE trial ${ }^{11}$ indicate that $40 \mathrm{mg}$ daily for $5 \mathrm{~d}$ is adequate for COPD exacerbations. My view is we're seeing and getting that same effect with lower steroid doses for COPD. Similarly in asthma, it seems that oral steroids at $1-2 \mathrm{mg} / \mathrm{kg} / \mathrm{d}$ (or $\sim 60-120 \mathrm{mg}$ daily) for prednisone is adequate for exacerbations. ${ }^{12,13}$

Peters: I agree that emergency department studies support this concept, but there are limited data about the optimal dose of corticosteroids in the ICU. One study, by Haskell et al, ${ }^{14}$ randomized subjects to $125 \mathrm{mg}$ every $6 \mathrm{~h}, 40 \mathrm{mg}$ every $6 \mathrm{~h}$, versus $15 \mathrm{mg}$ every $6 \mathrm{~h}$ of intravenous methylprednisolone. If you think about $15 \mathrm{mg}$ every $6 \mathrm{~h}$ of methylprednisolone, that's higher than what our guidelines recommend. This study demonstrated that $125 \mathrm{mg}$ was even better than $40 \mathrm{mg}$, and they were both better than the $15 \mathrm{mg}$ every $6 \mathrm{~h}$. The curves that compare the response to therapy crossed between 36 and $48 \mathrm{~h}$. So, the $\mathrm{FEV}_{1}$, after $2 \mathrm{~d}$ of therapy will be equivalent because most patients ultimately respond to $\beta$ agonists. However, if you look at a patient who might be going toward intubation or an intubated patient who might be difficult to ventilate, higher doses of intravenous steroids might be very beneficial. Our policy is still to use high-dose intravenous steroids for status asthmaticus for the first 24-48 $\mathrm{h}$ and then back down to guideline doses.

Wise: In asthma?

Peters: Yes, we're talking about patients with severe asthma in the ICU. We're not talking about the patients with asthma being treated in the emergency department. There are no studies that support such high doses except in the ICU in patients with status asthmaticus.

\section{REFERENCES}

1. Global Initiative for Asthma. Global strategy for asthma management and prevention. Updated 2017. http://ginasthma.org/ 2017-gina-report-global-strategy-for-asthmamanagement-and-prevention. Accessed July 24, 2017.

2. Vanden Burgt JA, Busse WW, Martin RJ, Szefler SJ, Donnell D. Efficacy and safety overview of a new corticosteroid, QVAR (hydrofluoroalkane-beclomethasone extrafine inhalation aerosol), in asthma. J Allergy Clin Immunol 2000;106:1209-1226.

3. Tantisira KG, Lake S, Silverman ES, Palmer LJ, Lazarus R, Silverman EK, et al. Corticosteroid pharmacogenetics: association of sequence variants in CRHR1 with improved lung function in asthmatics treated with inhaled corticosteroids. Hum Mol Genet 2004;13:1353-1359.

4. Hawkins GA, Lazarus R, Smith RS, Tantisira KG, Meyers DA, Peters SP, et al. The glucocorticoid receptor heterocomplex gene STIP1 is associated with improved lung function in asthmatic subjects treated with inhaled corticosteroids. J Allergy Clin Immunol 2009;123(6): 1376-1383.e7.

5. Tantisira KG, Lasky-Su J, Harada M, Murphy A, Litonjua AA, Himes BE, et al. Genomewide association between GLCCI1 and response to glucocorticoid therapy in asthma. N Engl J Med 2011;365:1173-1183. 
6. Tantisira KG, Damask A, Szefler SJ, Schuemann B, Markezich A, Su J, et al; SHARP Investigators. Genome-wide association identifies the $\mathrm{T}$ gene as a novel asthma pharmacogenetic locus. Am J Respir Crit Care Med 2012;185:1286-1291.

7. Phipatanakul W, Mauger DT, Sorkness RL, Gaffin JM, Holguin F, Woodruff PG, et al.; Severe Asthma Research Program. Effects of age and disease severity on systemic corticosteroid responses in asthma. Am J Respir Crit Care Med 2017;195(11):14391448.

8. Nelson HS, Busse WW, deBoisblanc BP, Berger WE, Noonan MJ, Webb DR, et al. Fluticasone propionate powder; oral corticosteroid sparing effect and improved lung function and quality of life in patients with severe chronic asthma. J Allergy Clin Immunol 1999;103(2 Pt 1)267-275.

9. Niewoehner DE, Erbland ML, Deupree RH, Collins D, Gross NJ, Light RW, et al. Effect of systemic glucocorticoids on exacerbations of chronic obstructive pulmonary disease. Department of Veterans Affairs Cooperative Study Group. N Engl J Med 1999; 340(25): 1941-1947.

10. Aaron SD, Vandemheen KL, Hebert P, Dales R, Stiell IG, Ahuja J, et al. Outpatient oral prednisone after emergency treatment of chronic obstructive pulmonary disease. N Engl J Med 2003;348(26):26182625.

11. Leuppi JD, Schuetz P, Bingisser R, Bodmer M, Briel M, Drescher T, et al. Shortterm vs conventional glucocorticoid therapy in acute exacerbations of COPD: The
REDUCE randomized clinical trial. JAMA 2013;309(21):2223-2231.

12. Edmonds ML, Camargo CA Jr, Pollack CV $\mathrm{Jr}$, Rowe BH. Early use of inhaled corticosteroids in the emergency department treatment of acute asthma. Cochrane Database Syst Rev 2003;(3):CD002308.

13. Rowe BH, Edmonds ML, Spooner $\mathrm{CH}$, Diner B, Camargo CA Jr. Corticosteroid therapy for acute asthma. Respir Med 2004; 98(4):275-284.

14. Haskell RJ, Wong BM, Hansen JE. A double-blind, randomized clinical trial of methylprednisolone in status asthmaticus. Arch Intern Med 1983;143:1324-1327.

* Michael T Newhouse MD, invited discussant. Dr Newhouse is the chief medical officer for InspiRx.

This article is approved for Continuing Respiratory Care Education credit. For information and to obtain your CRCE

(free to AARC members) visit

www.rcjournal.com 